\title{
It's Complicated: The Relationship Between Participation in Academic Coaching and Program Completion in Online Graduate Students
}

\author{
Tara Lehan, Michael Shriner \\ Northcentral University \\ Bethanne Shriner \\ University of Wisconsin-Stout
}

\begin{abstract}
This study extends prior research by investigating the relationship of synchronous, one-on-one academic coaching with program completion, comparing a random sample of students who participated in academic coaching to a matched sample of students who did not receive academic coaching in fully online graduate courses. The findings indicate that a previously observed relationship between academic coaching and persistence in online graduate students does not endure through program completion, although the relationship between several demographic and academic variables and program completion did remain statistically significant. In light of these findings, if the goal is to increase their odds of completion, it seems that students who are already engaging with an academic coach (due to either self-selection or faculty encouragement/requirement) might be encouraged to continue to do so. Moreover, a "booster" coaching session might be helpful. However, there is insufficient evidence to support the practice of requiring participation in academic coaching among students who do not do so on their own.
\end{abstract}

Keywords: distance education, online graduate students, learning center, academic coaching, graduation, completion, retention, persistence

Lehan, T., Shriner, B., \& Shriner, M. (2020). It's complicated: The relationship between participation in academic coaching and program completion in online graduate students. Online Learning, 24(3), 19-34. https://doi.org/ 10.24059/olj.v24i3.2142

\section{It's Complicated: The Relationship Between Participation in Academic Coaching and Program Completion in Online Graduate Students}

As of 2017, there were 868,708 fully online graduate students attending universities in the United States (Bastrikin, 2020). This number represent $28.9 \%$ of the total graduate student population of 1.4 million. However, the completion/retention/graduation rates of fully online graduate programs have traditionally fallen behind their face-to-face counterparts (Muljana \& Luo, 2019). Despite the rapid growth of online courses and programs, it remains unclear how to support learning and achievement most effectively in this context (Rakes \& Dunn, 2010). Slater and Davies (2020) report that online students value accessible, engaging, and assignment-related content, but 
faculty members report that they do not have sufficient time to complete all their job requirements optimally (Berebitsky \& Ellis, 2018). Academic coaches might represent an opportunity to promote not only learning, but also engagement, as well as persistence, retention, and completion among students (Bettinger \& Baker, 2011; Lehan, Hussey, \& Shriner, 2018). Scholarly attention has been paid to attrition rates in online graduate programs, which have been estimated to be as high as 50\% (Ivankova \& Stick, 2007) or even 70\% (Nettles \& Millet, 2006). A major reason for this high rate is that online graduate students tend to be working adults with multiple sometimes competing demands on their time (Brown, 2012).

Professionals in learning centers, such as academic coaching and/or tutoring centers, can offer support services that provide students with opportunities to engage with their course curriculum using different media, relearn concepts, and request further explanation (Fullmer, 2012). Even though online institutions may offer specialized support services for students, their brick-and-mortar counterparts are more likely to have traditional learning centers (Felder-Strauss et al., 2015). Whereas academic coaching has experienced continued growth at higher education institutions, likely due to its newer development as a student service, it has not been the focus of much research (Capstick, Harrell-Williams, Cockrum, \& West, 2019), with almost no previous research focusing on the outcomes and impacts associated with online learning centers. This paucity of research is concerning during a time when learning assistance is needed most, as more students enroll in online programs, but continue to struggle to a greater extent than their peers in face-to-face settings (Britto \& Rush, 2013).

\section{Review of Relevant Literature}

Tinto's (1993) model of institutional departure has been referenced in numerous publications (Alhojani, 2016) and frequently used to explain or predict whether a student will drop out (Nicoletti, 2019). Tinto argued that students must participate in formal (extracurricular activities) and informal (peer groups interactions) social systems. In addition, they must integrate into formal (academic performance) and informal (faculty/staff interactions) academic systems to learn and persist. Similarly, researchers have found that one of the most important factors related to students' persistence is their ability to make a meaningful connection with at least one member of the college or university community (e.g., Kuh, 2005). Likewise, Chambliss and Takacs (2014) argued that developing relationships with staff members, such as those fostered through academic coaching, can have a positive impact on student success. However, the outcomes and impacts associated with these relationships have been examined to a limited extent, especially among graduate and online students.

Findings are mixed regarding what learning centers do and how they function to support student learning and achievement (Truschel \& Reedy, 2009). For the most part, however, results of research have shown that students who choose to take advantage of support services at learning centers reportedly experience beneficial outcomes (e.g., Osborne, Parlier, \& Adams, 2019). For example, Lancer and Eatough (2018) used Interpretive Phenomenologial Analysis with nine undergraduates over an academic year to understand their expeirences of having had six academic coaching sessions each. They suggested that academic coaching offered benefits to time management, stress reduction, and overall academic confidence. Additionally, Oreopoulos, Petronijevic, Logel, and Beattie (2020) analyzed the responses of 3,000 undergraduates who experienced low-cost and elective text-message based coaching sessions and reported feelings of 
greater satisfaction and belonging to the university amongst the respondents. Conversely, in a pilot study, Sepulveda, Birnbaum, Finley, and Frye (2020) show no differences between 46 participants who experienced brief academic coaching and 45 participants who did not on measures of retention and GPA.

After reviewing the impact of thousands of student success initiatives from dozens of higher education institutions, Civitas Learning (2019) found that tutoring was associated with increased persistence among first-year students (5.2\% lift) and students who have completed four or more terms $(1.98 \%$ lift), with Black and Hispanic students experiencing greater increases in persistence than their white counterparts. In a fairly robust study, Bettinger and Baker (2011) found that students in a face-to-face context who participated in tutoring had significantly higher persistence rates $6,12,18$, and 24 months later and higher degree completion rates than those who did not. Capstick, Harrell-Williams, Cockrum, and West (2019) used a quasi-experimental nonequivalent post-test design with 1,434 students and reported that students who electivly engaged in acadmic coaching demonstrated increased GPAs, were more likely to be in good academic standing (had a GPA of at least a 2.0) and were more likely to be retained in the next semester than those students who did not participate in acaademic coaching. Similarly, Lehan et al. (2018) found that online graduate students who worked synchronously with an academic coach at an online learning center were significantly more likely to persist six to nine months later than a sample of students in the same course with the same faculty member at the same time who did not work with an academic coach. Specifically, after holding months since enrollment and GPA at follow-up constant, working with an academic coach even once increased the odds of persistence 2.66 times, suggesting that academic coaching can be a high-impact practice. Several researchers have reported a correlation between the number of visits to the learning center and improved student achievement (Cooper, 2010; Fullmer, 2012; Laskey \& Hetzel, 2011; Osborne et al., 2019), although Lehan et al. (2018) did not find support for such a relationship among online graduate students.

Given the divergent findings in the relevant scholarly literature, additional research is warranted to understand to what extent working with an academic coach is associated with longerterm persistence up to and including program completion. Such research can serve as a foundation for future investigations that can inform best practices in cocurricular learning assistance as well as efforts to improve student retention for online and/or graduate students. If higher education institutions provide academic coaching services as a persistence, retention, and/or completion initiative, it is critical that they evaluate under what conditions they are effective and use the findings to make continuous improvements (Robinson, 2015). Therefore, the purpose of this study was to examine the extent to which the previously reported impact of academic coaching on persistence (Lehan et al., 2018) endures through program completion. This study extends upon this previous work by examining the longer-term impacts of academic coaching. 


\section{Methods}

\section{Setting}

This study took place at a for-profit turned not-for-profit (in 2019) completely online university that primarily grants graduate degrees. When the data were originally collected, there were four schools: Education, Business and Technology Management, Psychology, and Marriage and Family Sciences. At this institution, students may set the pace at which they take courses. Also, a one-to-one model is employed, where every class size is 1, with the goal of greater personalization of the teaching and learning experience. In addition, a teaching through engagement model is used to guide instruction. At this institution, accountability for student learning and success is shared among not only faculty members and students who are working together, but also staff members, administrators, and all other institutional actors. At the institution, cocurricular learning opportunities, including personalized academic coaching, are available to all students. It is defined as the process of helping a student to examine academic concerns and perceived barriers to success. Anecdotal and empirical (e.g., Babcock, Lehan, \& Hussey, 2019) evidence existed at this institution that students' working with an academic coach one-on-one might result in greater persistence. Therefore, an evaluation was designed to determine the extent to which and under what conditions such a relationship might exist.

To enhance student learning and achievement, certified part-time academic coaches with graduate degrees are available at an internal online learning center. These professionals provide personalized cocurricular academic support in written communication and statistics to students in groups and one-on-one at no additional cost. Tiered levels of support (Tier 1: posted resources available 24/7; Tier 2: live chat; Tier 3: asynchronous one-on-one and synchronous group coaching; Tier 4: one-on-one synchronous academic coaching) are available to meet the unique needs of students from diverse backgrounds. The first two tiers are designed so that students can obtain answers and/or guidance surrounding common basic issues rapidly, whereas the two highest tiers are designed for students who need a higher level and/or different type of assistance. In synchronous one-on-one sessions, although students often present with an assignment on which they are feeling stuck, the focus is on the development of competence in the relevant learning outcome(s). Although there is no limit to the number of group sessions in which a student can participate each week, the maximum number of one-on-one sessions per week is two, except in special circumstances. WCOnline is used for scheduling, documentation, and asynchronous interactions. In synchronous sessions, the coach and student(s) meet via teleconference. The focus of coaching sessions is on the enhancement of student competence in specific areas related to institutional learning outcomes, specifically written communication and quantitative reasoning, as opposed to the completion of coursework or development of broader skills, such as time management. Relating to written communication, academic coaching might focus, for example, on the synthesis of literature or paraphrasing. With regard to quantitative reasoning, academic coaching might focus, for example, on levels of measurement or the steps in a specific statistical test. The coaches also aim to help students to become more self-directed in their learning.

All students who interact with a live academic coach while using the two highest tiers of support either synchronously or asynchronously receive a personalized coaching plan. It includes information about the skill(s) on which they worked, coaching strategies that were used, effectiveness of those strategies with supporting evidence, and steps that the student can take between sessions to continue to learn and achieve. A link to the recording of the session is also included in case students want to revisit it. Once the student and coach believe that the student has 
reached competence based on the university's definition according to Bloom's taxonomy, coaching for that skill ends, but can begin on another skill. These data were archived and the university's institutional review board approved the study protocol.

\section{Participants}

In April 2016, 160 graduate students who participanted in one-on-one synchronous academic coaching at a completely online university were selected using a randomization procedure from all students who participated in academic coaching at least once from October 1 through December 31, 2015 for inclusion in the academic coaching sample. Specifically, they were ordered by student identification number and every tenth student was selected. Data (including their student ID number, issue that prompted them to seek learning assistance, course, and faculty member) they entered before scheduling a coaching session were exported into an Excel spreadsheet. Information from the scheduling program (WCOnline), including number of academic coaching sessions, were added to the spreadsheet. Next, a matched sample of students who were in the same course with the same faculty member at the same time as each student in the academic coaching sample was created by an individual who was external to the research team who had no knowledge of the study's purpose. Even when students are at the same stage of their dissertation (i.e., in the same course), they did not interact through the course. That individual matched the pairs on gender, race, and age when possible. The goal was to identify a student who was as similar as possible in terms of demographic characteristics to each student in the academic coaching sample, except that the corresponding student in the matched sample did not work with an academic coach. The students' enrollment status (active/inactive) was not considered when selecting students in either sample.

In both the academic coaching and the matched samples, 60 (37.5\%) students were in the School of Business and Technology Management, 59 (36.9\%) were in the School of Education, 26 (16.3\%) were in the School of Psychology, and 15 (9.4\%) were in the School of Marriage and Family Sciences. For students in the academic coaching sample, 57 self-reported as White (35.6\%), 35 as Black/African-American (21.9\%), 15 as Hispanic/Latino (9.4\%), 7 as Asian (4.4\%), 3 as two or more races/ethnicities (1.9\%), 1 as Native American or other Pacific Islander (.6\%), and 42 reported no information on race/ethnicity shared (26.3\%). In the matched sample, 74 selfreported as White (46.3\%), 35 as Black/African-American (21.9\%), 8 as two or more races (5\%), 6 as Hispanic/Latino (3.8\%), 1 as Asian (.6\%), 1 as Native American or other Pacific Islander (.6\%) and 35 reported no information on race/ethnicity shared (21.9\%). Moreover, 123 of the 160 students in each sample were pursuing a doctoral degree. Table 1 provides details about the demographic and academic characteristics of the students in both samples. Among the students in the academic coaching sample, the average number of academic coaching sessions ranged from 1 to $208(\mu=16.9, \mathrm{SD}=30.4)$. However, as was the case in the previous study examining persistence 6 to 9 months later as the outcome of interest, the mode number of sessions was one. Specifically, 27 of these students $(16.8 \%$ ) visited the academic coaching center one time from October 1, 2015 through March 1, 2019.

\section{Procedure}

Following a review of the relevant literature and university data, student demographic and academic information for several variables that potentially influence program completion was obtained. In March 2019, an external team member provided updated enrollment status and other data for students in both the academic coaching and the matched sample to permit examination of 
the relationship between working with an academic coach and program completion. The recommended time to completion of graduate programs at the university ranges from 23 months to 56 months. As the average time since enrollment among the students in the samples was approximately 68 months (see Table 1), if they made timely progress, the students had sufficient time to complete their programs after working with an academic coach at the end of 2015, even if it was during their very first course in their program. Nevertheless, a record review was conducted to ensure that each student who did not graduate had sufficient time to complete their program if they remained continuously enrolled.

Table 1

Demographic and Academic Characteristics of Academic Coaching and Matched Samples

\section{Academic Coaching Sample Matched Sample}

$(n=160)$

$(n=160)$

Program Completion

(Percentages)

Yes $(51.3 \%)$

No $(48.8 \%)$

Yes $(44.4 \%)$

No $(55.6 \%)$

$\chi^{2}=1.51$

Months Since

Program

Enrollment*

(Means, Standard

$67.26(24.50)$

Deviations)

Years Since Last

Degree (Means,

Standard Deviations)

GPA of Content

Courses (Means,

Standard Deviations)

$12.88(8.40)$

$11.56(7.85)$

$68.58(24.76)$

$t(318)=.47$

$\begin{array}{ll} & \text { Women }(73.1 \%), \\ \text { Sex/Gender } & \text { Men }(22.5 \%), \\ \text { (Percentages) } & \begin{array}{l}\text { No information on } \\ \text { sex/gender shared } \\ (4.4 \%)\end{array}\end{array}$

Age (Means,

Standard Deviations)

Number of Coaching

Sessions (Means,

Standard Deviations)

Veteran Status
(Percentages)
History of Dismissal
(Percentages)

Veteran Status

Yes $(2.5 \%)$

No $(97.5 \%$

Yes $(31.3 \%)$

No $(68.8 \%)$
Women (66.3\%),

Men (28.8\%),

No information on

sex/gender shared

$\chi^{2}=1.83$

$p=.40$

$(5 \%)$

$44.4(\mathrm{SD}=10.57)$

$t(318)=1.38$

$p=.17$

$t(318)=7.01$

$0(0.0)$

$p=.00^{* *}$ 
It's Complicated:

The Relationship Between Participation in Academic Coaching and Program Completion in Online Graduate Students

* Months between program enrollment date and data analysis in March 2019

** significant $p<.05$ 
A prospective approach was employed to limit potential sources of bias. Given that the focus of the main analysis was on investigating differences in student program completion rates based on utilization of academic coaching services, a causal-comparative design was used. The outcome variable, program completion, was coded as a dichotomous variable. Students who completed their program by the time the data were analyzed (March 2019) had a 1 on the outcome variable, whereas those who did not make timely completion or withdrew or were dismissed from their program had a 0 .

As sequentially delineated by Field (2017), preliminary analyses were first conducted to determine whether there were significant differences between the academic coaching sample and the matched sample (see Table 1) requiring the need to control for certain variables. Next, the bivariate relationships between each potential predictor variable and the outcome variable of interest (program completion) were examined. Finally, for the main analyses, binary logistic regressions were run with four different models including all the predictor variables that had a significant relationship with program completion in Table 2.

\section{Results}

In preliminary analyses (as can be see in Table 1), no statistically significant differences in demographic and academic characteristics were found between the students in the academic coaching sample and those in the matched sample $(\alpha<.05)$. As shown in Table 2 , several of the potential predictor variables were found to be significantly related to program completion in bivariate analyses, including number of months since program enrollment, number of years since attainment of the last degree, GPA for content courses, history of program dismissal due to not making satisfactory academic progress or other reasons, age, and financial aid status. Whereas the number of academic coaching sessions (a ratio-level variable) was found to be significantly related to program completion in the academic coaching sample $\left(r_{s}=.170, p=.03, n=160\right)$, when the matched sample was added to the analysis, the relationship between working with an academic coach and program completion was no longer statistically significant. This was true, regardless of whether participation in academic coaching was measured as a categorical (yes/no) $\left(r_{s}=.069, p=\right.$ $.22, n=320)$ or an interval (number of sessions) $\left(r_{s}=.054, p=.34, n=320\right)$ variable.

Table 3 shows the results of the four different multivariate logistic regressions that were run:

(1) Model 1: The Academic Coaching Sample only and the predictor of "Number of Coaching Sessions";

(2) Model 2: Both the Academic Coaching Sample and the Matched Sample, dropping the "Number of Coaching Sessions" and adding "Academic Coaching (Yes/No)";

(3) Model 3: Both the Academic Coaching Sample and the Matched Sample, dropping "Academic Coaching (Yes/No)" and adding "Number of Coaching Sessions," and;

(4) Model 4: Both the Academic Coaching Sample and the Matched Sample and both "Academic Coaching (Yes/No) and "Number of Coaching Sessions." 
The Relationship Between Participation in Academic Coaching and Program Completion in Online Graduate Students

Table 2

Bivariate Relationships Between Each Potential Predictor Variable and Program Completion

\begin{tabular}{|c|c|c|c|c|c|c|c|c|c|}
\hline & $\begin{array}{l}\text { Program } \\
\text { Completion }\end{array}$ & $\begin{array}{l}\text { Academic } \\
\text { Coaching } \\
\text { (Yes/No) }\end{array}$ & $\begin{array}{l}\text { Number } \\
\text { of } \\
\text { Coaching } \\
\text { Sessions }\end{array}$ & $\begin{array}{l}\text { Months } \\
\text { Since } \\
\text { Enrollment }\end{array}$ & $\begin{array}{l}\text { Veteran } \\
\text { Status }\end{array}$ & $\begin{array}{l}\text { Years } \\
\text { Since } \\
\text { Last } \\
\text { Degree }\end{array}$ & $\begin{array}{l}\text { GPA } \\
\text { for } \\
\text { Content } \\
\text { Courses }\end{array}$ & $\begin{array}{l}\text { History } \\
\text { of } \\
\text { Dismissal }\end{array}$ & Age \\
\hline $\begin{array}{l}\text { Academic } \\
\text { Coaching } \\
\text { (Yes/No) }\end{array}$ & .069 & & & & & & & & \\
\hline $\begin{array}{l}\text { Number of } \\
\text { Coaching } \\
\text { Sessions }\end{array}$ & .054 & $.366^{*}$ & & & & & & & \\
\hline $\begin{array}{l}\text { Veteran } \\
\text { Status }\end{array}$ & -.007 & -.079 & -.047 & & & & & & \\
\hline $\begin{array}{l}\text { Months } \\
\text { Since } \\
\text { Enrollment }\end{array}$ & $.416^{*}$ & -.027 & -.042 & -.161 & & & & & \\
\hline $\begin{array}{l}\text { Years Since } \\
\text { Last } \\
\text { Degree }\end{array}$ & $.278 *$ & .081 & .100 & $.402 *$ & $-.130 *$ & & & & \\
\hline $\begin{array}{l}\text { GPA for } \\
\text { Content } \\
\text { Courses }\end{array}$ & $.413 *$ & .057 & .033 & $.347^{*}$ & -.053 & $.367^{*}$ & & & \\
\hline $\begin{array}{l}\text { History of } \\
\text { Dismissal }\end{array}$ & $-.579 *$ & -.104 & $-.133 *$ & $-.165^{*}$ & .009 & $-.267 *$ & $-.498 *$ & & \\
\hline Age & $.151 *$ & .076 & .092 & $.239 *$ & -.036 & $.418 *$ & $.181^{*}$ & $.180^{*}$ & \\
\hline $\begin{array}{l}\text { Financial } \\
\text { Aid Status }\end{array}$ & $-.199 *$ & .038 & -.037 & -.032 & $-.400 *$ & $-.137 *$ & $-.224 *$ & -.068 & -.155 \\
\hline
\end{tabular}


Table 3

Results of Multivariate Logistic Regression with Graduation as an Outcome

\begin{tabular}{|c|c|c|c|c|}
\hline & $\begin{array}{l}{ }^{1} \text { Model 1: } \\
\text { The Academic } \\
\text { Coaching Sample } \\
\text { only and the } \\
\text { predictor of "Number } \\
\text { of Coaching } \\
\text { Sessions," }\end{array}$ & $\begin{array}{l}{ }^{2} \text { Model 2: } \\
\text { Both the Academic } \\
\text { Coaching Sample } \\
\text { and the Matched } \\
\text { Sample, dropping the } \\
\text { "Number of } \\
\text { Coaching Sessions" } \\
\text { and adding } \\
\text { "Academic Coaching } \\
\text { (Yes/No)" }\end{array}$ & $\begin{array}{l}\text { 33} \text { Model 3: } \\
\text { Both the Academic } \\
\text { Coaching Sample } \\
\text { and the Matched } \\
\text { Sample, dropping } \\
\text { "Academic Coaching } \\
\text { (Yes/No)" and } \\
\text { adding "Number of } \\
\text { Coaching Sessions," }\end{array}$ & $\begin{array}{l}{ }^{4} \text { Model 4: } \\
\text { Both the Academic } \\
\text { Coaching Sample } \\
\text { and the Matched } \\
\text { Sample and both } \\
\text { "Academic Coaching } \\
\text { (Yes/No) and } \\
\text { "Number of } \\
\text { Coaching Sessions," }\end{array}$ \\
\hline Constant B(SE) & $-10.12(3.38)^{*}$ & $-5.33(1.87)^{* *}$ & $-5.13(1.82)^{* *}$ & $-5.28(1.87)^{* *}$ \\
\hline $\begin{array}{l}\text { Number of } \\
\text { Coaching } \\
\text { Sessions B(SE) }\end{array}$ & $-.00(.00)$ & & $-.00(.00)$ & $-.00(.00)$ \\
\hline $\begin{array}{l}\text { Academic } \\
\text { Coaching } \\
\text { (Yes/No) } \\
\text { B(SE) }\end{array}$ & & $.17(.32)$ & & $.21(.34)$ \\
\hline $\begin{array}{l}\text { Months Since } \\
\text { Enrollment } \\
\text { B(SE) }\end{array}$ & $.06(.01)^{*}$ & $.05(.00)^{* *}$ & $.05(.00)^{* *}$ & $.05(.01)^{* *}$ \\
\hline $\begin{array}{l}\text { Years Since } \\
\text { Last Degree } \\
\mathrm{B}(\mathrm{SE})\end{array}$ & $-.02(.03)$ & $.00(.02)$ & $.00(.02)$ & $.00(.02)$ \\
\hline $\begin{array}{l}\text { GPA for } \\
\text { Content } \\
\text { Courses B(SE) }\end{array}$ & $2.13(.86)^{*}$ & $.95(.49)^{*}$ & $.92(.48)$ & $.94(.49)$ \\
\hline $\begin{array}{l}\text { History of } \\
\text { Program } \\
\text { Dismissal } \\
\text { B(SE) }\end{array}$ & $-3.82(.85)^{* *}$ & $-3.20(.48)^{* *}$ & $-3.25(.48)^{* *}$ & $-3.23(.48)^{* *}$ \\
\hline Age B(SE) & $.01(.03)$ & $-.00(.02)$ & $-.00(.02)$ & $-.00(.02)$ \\
\hline $\begin{array}{l}\text { Financial Aid } \\
\text { Status B(SE) }\end{array}$ & $-1.03(.62)$ & $-.80(.41)^{*}$ & $-.80(.41)^{*}$ & $-.81(.42)^{*}$ \\
\hline
\end{tabular}

*significant $p<.05 ; * *$ significant $p<.01$

${ }^{1} R^{2}=. .43\left(\right.$ Cox \& Snell), ..57 (Nagelkerke). Model $\left.\chi^{2}(7)=105.47, p<.001\right)$.

${ }^{2} R^{2}=.45$ (Cox \& Snell), .60 (Nagelkerke). Model $\left.\chi^{2}(7)=189.81, p<.001\right)$.

${ }^{3} R^{2}=.48$ (Cox \& Snell), .59 (Nagelkerke). Model $\left.\chi^{2}(7)=189.56, p<.001\right)$.

${ }^{4} R^{2}=.45$ (Cox \& Snell), .60 (Nagelkerke). Model $\left.\chi^{2}(8)=189.97, p<.001\right)$. 
Each of these models include all the variables that had a statistically significant relationship with program completion included in Table 2 (months since enrollment, years since earning the last degree, GPA for content courses, history of program dismissal, age, and financial aid status). The relationship between program completion and both months since enrollment and history of program dismissal status remained significant across all four models, whereas the relationship with GPA for content courses was only significant in the first two models. Financial aid status was significant in models two, three, and four. The relationship with years since last degree, number of coaching sessions, whether or not the participants ever attended a coaching session, and age were not significant in any of the models. The models correctly predicted whether a student graduated or not $83.1 \%$ of the time for models 1,2 , and 4 and $81.9 \%$ of the time for model 3 .

\section{Discussion}

Consistent with Tinto's (1993) model of institutional departure, numerous scholars (e.g., Chambliss \& Takacs, 2014; Kuh, 2005) have argued that students' persistence and success are related to their ability to make a meaningful connection with at least one member of the college or university community. Therefore, it seems that engaging with a learning assistance professional in academic coaching should have a positive impact on students' program completion. There is evidence to suggest that academic coaching can have beneficial outcomes and impacts (e.g., Lehan et al., 2018; Bettinger \& Baker, 2011; Osborne et al., 2019). However, much of the previous research involved undergraduate students at traditional brick-and-mortar institutions, neglecting graduate and online students. Further, the existing body of literature is plagued by methodological limitations, as evidenced by previous researchers' not including a matched sample, holding constant other influential variables, or examining outcomes and impacts in the longer term in their analyses. To add to the relevant literature, the purpose of this study was to determine if the association between participation in synchronous one-on-one academic coaching and persistence among online graduate students (as reported in Lehan et al., 2018) at one completely online university endured in the longer-term through program completion in the same two groups of students (i.e., those who engaged in academic coaching and a matched sample of their peers in the same course with the same faculty member at the same time who did not). Whereas the findings of Lehan et al. (2018) do seem to support the notion that students' integrating with formal and informal academic systems (in this case, with an academic coach in co-curricular learning support) is associated with their persistence, the findings of this study suggest that this relationship might not endure over time and/or in the face of other factors.

In the preliminary analyses of this study, no statistically significant differences in demographic or academic characteristics were found between students who chose to participate in academic coaching and those who did not. Commonly described in the literature is the notion that students often view cocurricular learning assistance, such as academic coaching, as being associated with experiencing difficulties in courses; therefore, they sometimes are hesitant to seek support (Babcock et al., 2019). Additionally, older, first-in-family students (similar to the participants in this study), often lack the time, confidence, and belief that they need additional support, despite the apparent need for academic skills and technology support (Stone \& O'Shea, 2019). However, learning assistance is not only for students who are at-risk (Arendale, 2010), as it seems the students in the academic coaching sample in this study understood. Future researchers might examine under what conditions students chose to engage in academic coaching to promote 
understanding of the extent to which those conditions influence the relationship between academic coaching and outcomes, including program completion.

Osborne et al. (2019) reported that academic coaching had a positive impact on undergraduate students' perceived academic outcomes, with those attending more regular sessions reporting a greater academic impact. Specifically, the perceived impact was higher for students who engaged in academic coaching five or more times than for students that had done so one to two times, with moderate to high practical importance for a relatively few number of interactions. Other researchers (e.g., Fullmer, 2012; Laskey \& Hetzel, 2011) also found a correlation between the number of learning center visits and improved undergraduate student performance. In the previous study of the relationship involving the same two samples of online graduate students examined in this study, participation in synchronous academic coaching was found to increase the odds of persistence six to nine months later 2.66 times (Lehan et al., 2018). In this follow-up study of objective outcomes of online graduate students who participated in academic coaching, attending more sessions (or even one sessison) was not associated with greater odds of program completion. In academic coaching sample, although the average number of academic coaching sessions was approximately 17, nearly one-fifth of them visited the learning center only one time. That is, many of them never returned to academic coaching after their first experience. It is unclear why they made this decision, although the importance of students' willingness to access online learning assistance (Brown, Hughes, Keppell, Hard, \& Smith, 2015) and finding them to be helpful (Price, Richardson, \& Jelfs, 2007) has been noted. Slater and Davies (2020) contend that online graduate students value resources that are accessible, engaging, content/assignment specific, and approximate a more trational campus experience. In addition, Dawson (2016) found that online graduate students' sense of community was positively related to satisfaction, engagement, and retention. Given that researchers have reported evidence of a relationship between participation in academic coaching (which should attempt to offer the resources that are most valued) and shorterterm student outcomes, future researchers might examine under what conditions students do and do not continue to use this service. Moreover, no research was found in which the researchers attempted to explain this relationship. That is, it remains unclear if it can be explained through the relationship with an academic coach and/or the instructional strategies that are used to assist students in their learning. Future researchers might investigate such potential explanations.

Nevertheless, in this study, the relationship between participation in synchronous one-onone academic coaching and program completion was not statistically significant. In general, this finding is consistent with previous results showing the limited responsiveness of students to nudging, low-cost interventions designed to change behavior predictably (e.g., Oreopoulous \& Pertronijevic, 2019). Although Osborne et al. (2019) reported that students at their institution who participated in academic support programs tended to have higher retention rates and GPAs in the future compared to those who did not, they seemingly did not conduct analyses to determine whether the differences were statistically significant and/or practically important. Overall, given that few previous researchers have included a matched sample of students in long-term examinations of the impacts of academic coaching, it is difficult to know if previously- reported relationships would follow a similar trend as was found in this study. It is possible that one or more "booster" sessions are needed to maintain the impact of academic coaching on student persistence in the longer term. Moreover, it might be that different types of academic coaching (e.g., one focusing on how to be a successful student versus one focusing on how to develop competence in learning outcomes) have distinct impacts for different students. 
In this study, after holding years since last degree, age, GPA for content courses, and financial aid status constant, months since enrollment and history of program dismissal were predictive of program completion. These findings are consistent with those of previous research on factors associated with persistence in online programs (e.g., Hart, 2012). Although it is not necessarily remarkable that students with a history of program dismissal might have lower odds of completing their program, it is more surprising that greater time since program enrollment was found to be associated with higher odds of completion. It would seem that students' requesting leaves of absence and extensions as well as having to retake courses due to their not meeting expectations would put them more at risk of noncompletion. It is possible that the examination period simply was not long enough to capture these trends. Further, it is possible that students who take more time in their educational trajectory are more deliberate, perseverant, and even resilient than other students.

In sum, it seems that the relationship between participation in synchronous one-on-one academic coaching and student achievement might be more complicated that initially thought. It appears that it can improve persistence of online graduate students in the shorter term (i.e., six to nine months later). However, this relationship seemingly does not endure over years. If this service is provided at an institution to increase students' odds of completion, it seems that those who are already engaging with an academic coach (due to either self-selection or faculty encouragement/requirement) might be encouraged through informal and informal interactions to continue to do so. Moreover, it is possible that one or more "booster" coaching sessions might be helpful. Nevertheless, based on these findings, there is insufficient evidence to support the practice of requiring participation in academic coaching among students who do not do so on their own.

\section{Limitations}

Limitations are inherent to any empirical investigation. As such, the findings reported here should be considered with a number of caveats. First, the population from which the samples were drawn consisted entirely of online graduate students. In addition, on average, the students in this study were in the 40s and it had been approximately 12 years since they were last students. As such, the ability to generalize the findings to other populations, including students in traditional programs, is limited. Second, as a quantitative, causal-comparative study in which participants could not be assigned randomly to a group in an ethical manner, causation could not be established. Other factors, including the participants' age and time since last degree, might explain the findings. This special population might require more and/or a different type of support than students in traditional programs. Third, although every attempt was made to identify a student as close to each student demographically in the matched sample, it was not always possible. Therefore, there were demographic differences (although not statistically different) between pairs in some cases, for example, in gender and/or age. It is possible that these differences influenced the findings. Fourth, as with any investigation, it is possible that one or more correlations are spurious. For example, the influence of some variables that may be related to a student's willingness and/or ability to both seek academic support and ultimately graduate were not controlled for. Fifth, the outcome variable was dichotomized without regard for whether the students made timely completion or were withdrawn or dismissed at any point. Finally, although the coaches follow a protocol, any variations in coaching style were not analyzed. Relatedly, aspects of the relationship between student and coach were not analyzed.

Despite these limitations, the study has a number of strengths that make a contribution to the extant literature. First, variables were selected based upon a critical review of relevant research 
and theory. Second, a prospective design was employed, which limits potential sources of selection bias. Third, the use of a matched sample and preliminary analyses offers compelling support for the final model within the main analysis. Additionally, randomization was used to create both the academic coaching center and matched samples.

\section{Conclusion}

This study contributed to the literature by examining online graduate students, who are understudied, and including a matched sample of students in the same course with the same faculty member at the same time as the students who participated in academic coaching. The results of analyses of the academic coaching sample only converged with previous findings that participation in a greater number of sessions was associated with greater odds of persistence (in this case, through completion). However, when the matched sample also was included in the analysis, this relationship was no longer statistically significant. Therefore, it appears as though the association between academic coaching and longer-term student outcomes is more complex than originally thought. Future researchers might examine under what conditions students choose to participate in and continue academic coaching as well as what factors mediate and/or moderate the relationship between participation in academic coaching and shorter- and longer-term student outcomes.

\section{Acknowledgments}

We would like to thank Erika Mendoza for her assistance in the identification of students to create the matched sample and provision of updated data for students in both samples. Additionally, this work was supported by an award from Northcentral University. This support does not necessarily imply endorsement by the university of the research conclusions.

\section{Disclosure Statement}

The authors declare no financial interest or benefit arising from the direct applications of this research. 


\section{References}

Aljohani, O. (2016). A comprehensive review of the major studies and theoretical models of student retention in higher education. Higher Education Studies, 6(2), 18. https://doi.org/10.5539/hes.v6n2p1

Arendale, D. R. (2010). Access at the crossroads-Learning assistance in higher education. ASHE Higher Education Report, 35(6), 1-145.

Babcock, A., Lehan, T., \& Hussey, H. D. (2019). Mind the Gaps: An Online Learning Center's Needs Assessment. Learning Assistance Review (TLAR), 24(1).

Bastrikin, A. (2020). Online Education Statistics. https://educationdata.org/online-educationstatistics/

Berebitsky, D., \& Ellis, M. K. (2018). Influences on personal and professional stress on higher education faculty. Journal of the Professoriate, 9(2), 88-110.

Bettinger, E. P., \& Baker, R. (2014). The effects of student coaching: An evaluation of a randomized experiment in student mentoring. Educational Evaluation and Policy Analysis, 36(1), 3-19.

Britto, M., \& Rush, S. (2013). Developing and implementing comprehensive student support services for online students. Journal of Asynchronous Learning Networks, 17(1), 29-42.

Brown, P. (2012). Degree attainment for adult learners. American Council on Education.

Brown, M., Hughes, H., Keppell, M., Hard, N., \& Smith, L. (2015). Stories from students in their first semester of distance learning. International Review of Research in Open and Distributed Learning, 16(4), 1-17.

Capstick, M. K., Harrell-Williams, L. M., Cockrum, C. D. \& West, S. L. (2019). Exploring the effectiveness of academic coaching for academically at-risk college students. Innovative Higher Education, 44, 219-231.

Chambliss, D. F., \& Takacs, C. G. (2014). How college works. Harvard University Press.

Civitas Learning (2019). What really works: A review of student success initiatives. https://media.civitaslearning.com/wpcontent/uploads/sites/3/2020/02/Civitas_Learning_What_Really_Works_Report.pdf

Cooper, E. (2010). Tutoring center effectiveness: The effect of drop-in tutoring. Journal of College Reading and Learning, 40(2), 21-34.

Dawson, T. L. (2016). An analysis of the effects of a virtual community on mature learners' feelings of isolation within online programs [Unpublished dissertation]. Northcentral University.

Felder-Strauss, J., Franklin, P., Machuca, A., Self, S., Offil, T., \& Kuhlman, B. (2015). Best practices and creation of an online tutoring center for accounting, finance, and economic disciplines. International Journal of Education Research, 10(1), 39-52.

Field, A. (2017). Discovering statistics using IBM SPSS statistics (5th ed). Sage Publications.

Fullmer, P. (2012). Assessment of tutoring laboratories in a learning assistance center. Journal of College Reading and Learning, 42(2), 67-89. 
Hart. C. (2012). Factors associated with student persistence in an online program of study: A review of the literature. Journal of Interactive Online Learning, 11(1), 19-42.

Ivankova, N. V., \& Stick, S. L. (2007). Students' persistence in a distributed doctoral program in educational leadership in higher education: A mixed methods study. Research in Higher Education, 48(1), 93-135.

Kuh, G. D. (2005). Student engagement in the first year of college. In M. L. Upcraft, J. N. Gardner, and B. O. Barefoot (Eds.), Challenging and supporting the first-year student: A handbook for improving the first year of college (pp. 86-107). Jossey-Bass.

Lancer, N., \& Eatough, V. (2018). One-to-one coaching as a catalyst for personal development. An interpretive analsysis of coaching undergraduates at a UK university. International Coaching Psychology Review, 13, 1-25.

Laskey, M. L., \& Hetzel, C. J. (2011). Investigating factors related to retention of at-risk college students. Learning Assistance Review, 16(1), 31-43.

Lehan, T. J., Hussey, H. D., \& Shriner, M. (2018). The influence of academic coaching on persistence in online graduate students. Mentoring \& Tutoring: Partnership in Learning, 26(3), 289-304.

Muljana, P. S., \& Luo, T. (2019). Factors contributing to student retention in online learning and recommended strategies for improvement: A systematic literature review. Journal of Information Technology Education: Research, 18, 19-57. doi: 10.28945/4182

Nettles, M. T., \& Millett, C. M. (2006). Three magic letters: Getting to Ph.D. Johns Hopkins University Press.

Nicoletti, M. d. C. (2019). Revisiting the Tinto's theoretical dropout model. Higher Education Studies, 9(2), 52-64.

Oreopoulos, P., \& Petronijevic, U. (2019). The remarkable unresponsiveness of college students to nudging and what we can learn from it (No. w26059). National Bureau of Economic Research.

Oreopoulos, P., Petronijevic, U., Logel, C., \& Beattie, G. (2020). Improving non-academic student outcomes using online and text-message coaching. Journal of Economic Behavior \& Organization, 171, 342-360.

Osborne, J. D., Parlier, R., \& Adams, T. (2019). Assessing impact of academic interventions through student perceptions of academic success. Learning Assistance Review, 24(1), 9-26.

Packham, G., Jones, P., Miller, C., \& Thomas, B. (2004). E-learning and retention: Key factors influencing student withdrawal. Education+ Training, 46(6/7), 335-342.

Price, L., Richardson, J. T., \& Jelfs, A. (2007). Face-to-face versus online tutoring support in distance education. Studies in Higher Education, 32(1), 1-20.

Rakes, G. C., \& Dunn, K. E. (2010). The impact of online graduate students' motivation and self-regulation on academic procrastination. Journal of Interactive Online Learning, 9(1), 78-93. 
Robinson, C. E. (2015). Academic/success coaching: A description of an emerging field in higher education. [Doctoral dissertation, University of South Carolina-Columbia].UMI Dissertation Publishing.

Sepulveda, A., Birnbaum, M., Finley, J. B., \& Frye, S. (2020) Coaching college students who have expressed an interest in leaving: A pilot study. Coaching: An International Journal of Theory, Research and Practice, 13(1), 8-15. doi: 10.1080/17521882.2019.1574847

Slater, D. R., \& Davies, R. (2020). Student preferences for learning resources on a land-based postgraduate online degree program. Online Learning, 24, 140-161.

Stone, C., \& O’Shea, S. (2019). Older, online and first: Recommendations for retention and success. Australasian Journal of Educational Technology, 35, 57-69.

Tinto, V. (1993). Leaving college: Rethinking the causes and cures of student attrition (2nd ed.). University of Chicago Press.

Truschel, J., \& Reedy, D. L. (2009). National survey-What is a learning center in the $21^{\text {st }}$ century? Learning Assistance Review, 14(1), 9-22. 